Provided for non-commercial research and educational use only. Not for reproduction or distribution or commercial use.

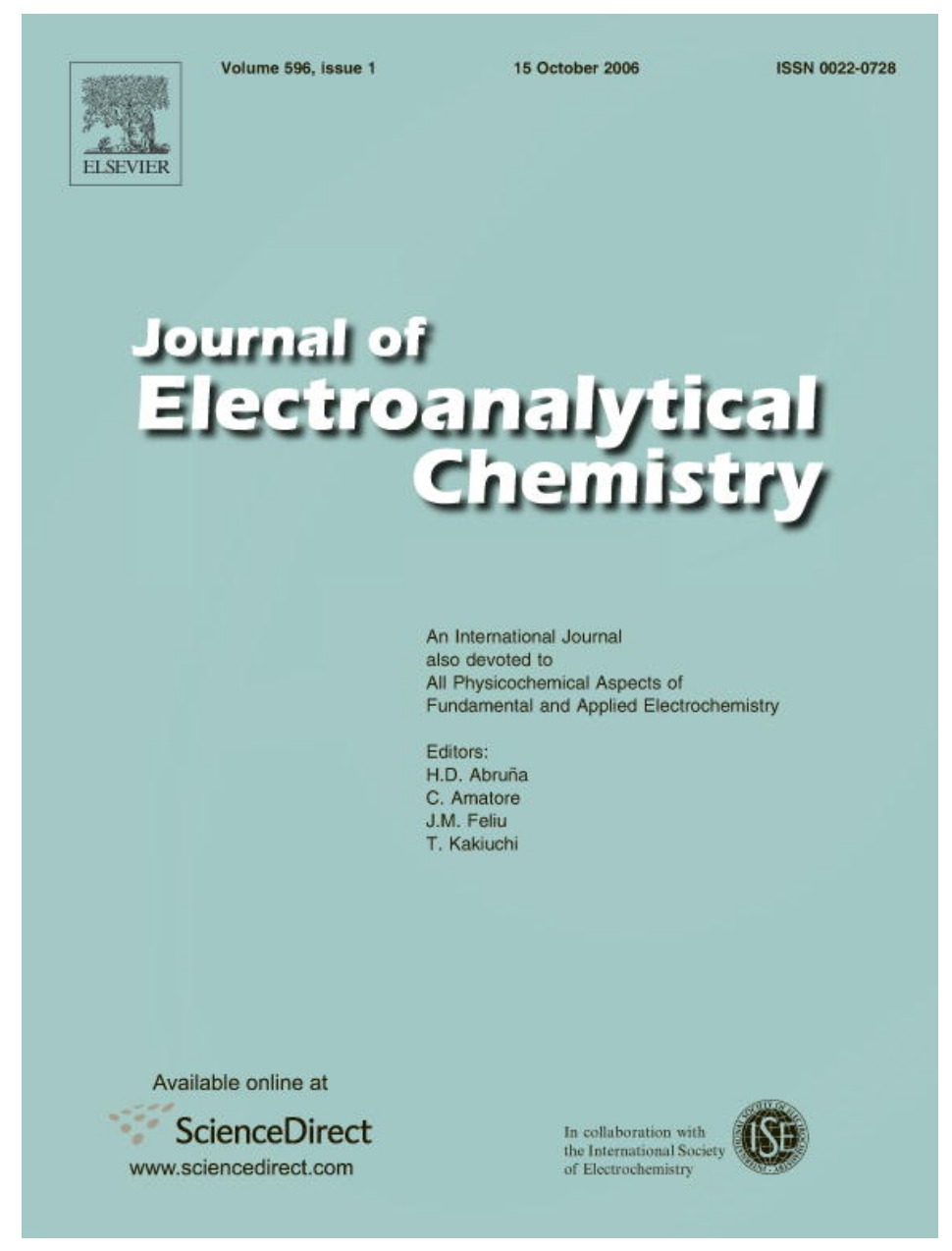

This article was originally published in a journal published by Elsevier, and the attached copy is provided by Elsevier for the author's benefit and for the benefit of the author's institution, for non-commercial research and educational use including without limitation use in instruction at your institution, sending it to specific colleagues that you know, and providing a copy to your institution's administrator.

All other uses, reproduction and distribution, including without limitation commercial reprints, selling or licensing copies or access,

or posting on open internet sites, your personal or institution's website or repository, are prohibited. For exceptions, permission may be sought for such use through Elsevier's permissions site at: 


\title{
Metal speciation dynamics in colloidal ligand dispersions. Part 3: Lability features of steady-state systems
}

\author{
J.P. Pinheiro ${ }^{\mathrm{a}, *}$, R.F. Domingos ${ }^{\mathrm{b}}$, M. Minor ${ }^{\mathrm{c}}$, H.P. van Leeuwen ${ }^{\mathrm{c}}$ \\ a CBME, Departamento de Química e BioquímicalFCT, Universidade do Algarve, Campus de Gambelas, 8005-139 Faro, Portugal \\ b $C M Q A$, Departamento de Química e BioquímicalFCT, Universidade do Algarve, Campus de Gambelas, 8005-139 Faro, Portugal \\ c Laboratory of Physical Chemistry and Colloid Science, Wageningen University, Dreijenplein 6, 6703 HB Wageningen, The Netherlands
}

Received 3 May 2006; received in revised form 2 July 2006; accepted 5 July 2006

Available online 9 August 2006

\begin{abstract}
A lability criterion is developed for dynamic metal binding by colloidal ligands with convective diffusion as the dominant mode of mass transport. Scanned stripping chronopotentiometric measurements of $\mathrm{Pb}(\mathrm{II})$ and $\mathrm{Cd}(\mathrm{II})$ binding by carboxylated latex core-shell particles were in good agreement with the predicted values. The dynamic features of metal ion binding by these particles illustrate that the conventional approach of assuming a smeared-out homogeneous ligand distribution overestimates the lability of a colloidal ligand system. Due to the nature of the spatial distribution of the binding sites, the change in lability of a metal species with changing ligand concentration depends on whether the ligand concentration is varied via manipulation of the $\mathrm{pH}$ (degree of protonation) or via the particle concentration. In the former case the local ligand density varies, whereas in the latter case it is constant. This feature provides a useful diagnostic tool for the presence of geometrically constrained binding sites.
\end{abstract}

(C) 2006 Elsevier B.V. All rights reserved.

Keywords: Metal speciation; Colloidal dispersions; Lability; Stripping chronopotentiometry

\section{Introduction}

In colloidal metal complex systems the spatial distributions of ligand and bound metal are constrained by geometrical and site distribution features of the particles. This feature has important consequences for the dynamic properties of the metal species. For ligands located on the surface of colloidal particles it has already been shown that the dynamic metal speciation features arise from the coupling between the chemical kinetics of complex formation/dissociation and the local diffusion-controlled transport of metal ions to/from the particle [1]. That led us to introduce the concept of 'generalized' rates of association and dissociation for colloidal metal complexes, $k_{\mathrm{a}}^{*}$ and $k_{\mathrm{d}}^{*}$

\footnotetext{
${ }^{*}$ Corresponding author. Tel.: +351 289 800905; fax: +351 289800066. E-mail address: jpinhei@ualg.pt (J.P. Pinheiro).
}

[1], which may differ by several orders of magnitude from their homogeneous solution counterparts, $k_{\mathrm{a}}$ and $k_{\mathrm{d}}$. The conventional approach of taking a colloidal ligand dispersion as a smeared-out homogeneous solution [2-4] overestimates both the dynamics and the lability of the colloidal metal complexes.

Colloidal ligands are typical components of natural waters [5] and electrochemical techniques have been extensively applied to metal speciation analysis in such media [6]. We have proposed electrochemical lability criteria for colloidal metal species under conditions where diffusion is the dominant mode of mass transport [7], such as in direct voltammetry of non-stirred solutions. However, due to their lower detection limit, stripping voltammetric techniques are usually preferred over direct methods for speciation analysis of natural waters [6]. During the deposition step of stripping methods, which is the decisive one for speciation analysis, the solution is usually stirred, and thus convective diffusion is the relevant mode of mass transport. 


\begin{tabular}{|c|c|c|c|}
\hline \multicolumn{4}{|c|}{ Nomenclature } \\
\hline \multicolumn{2}{|c|}{ Symbols } & $k_{\mathrm{a}}^{\prime}$ & $=k_{\mathrm{a}}^{\prime} c_{\mathrm{L}, \mathrm{T}}, \mathrm{s}^{-1}$ \\
\hline $\begin{array}{l}a \\
A\end{array}$ & $\begin{array}{l}\text { radius of the colloidal particle, } \mathrm{m} \\
\text { electrode surface area, } \mathrm{m}^{2}\end{array}$ & $k_{\mathrm{a}}^{*}$ & $\begin{array}{l}\text { generalized association rate constant of the } \\
\text { complex } \mathrm{ML}, \mathrm{mol}^{-1} \mathrm{~m}^{3} \mathrm{~s}^{-1}\end{array}$ \\
\hline$C_{i}$ & $\begin{array}{l}\text { coarse grained concentration of species } i, \\
\mathrm{~mol} \mathrm{~m}^{-3}\end{array}$ & $k_{\mathrm{d}}$ & $\begin{array}{l}\text { dissociation rate constant of the complex ML, } \\
\mathrm{s}^{-1}\end{array}$ \\
\hline$C_{i}^{*}$ & $\begin{array}{l}\text { coarse grained concentration of species } i \text { in the } \\
\text { bulk, } \mathrm{mol} \mathrm{m}^{-3}\end{array}$ & $k_{\mathrm{d}}^{*}$ & $\begin{array}{l}\text { generalized dissociation rate constant of the } \\
\text { complex ML, } \mathrm{s}^{-1}\end{array}$ \\
\hline$C_{\mathrm{M}, \mathrm{T}}^{*}$ & $\begin{array}{l}\text { total metal coarse grained concentration in the } \\
\text { bulk, } \mathrm{mol} \mathrm{m}^{-3}\end{array}$ & $K_{\mathrm{os}}$ & $\begin{array}{l}\text { stability constant for outer-sphere complexes, } \\
\mathrm{mol}^{-1} \mathrm{~m}^{3}\end{array}$ \\
\hline$c_{\mathrm{M}}^{*}$ & concentration of the metal in the bulk, $\mathrm{mol} \mathrm{m}^{-3}$ & $k_{-w}$ & water loss rate constant, $\mathrm{s}^{-1}$ \\
\hline$c_{\mathrm{M}^{0}}^{*}$ & concentration of the reduced metal in the bulk & $L$ & lability criterion \\
\hline$c_{\mathrm{L}}$ & $\begin{array}{l}\text { of the mercury drop, mol m} \\
\text { concentration of the ligand, } \mathrm{mol} \mathrm{m}^{-3}\end{array}$ & $L^{*}$ & $\begin{array}{l}\text { lability criterion for the dynamic colloidal } \\
\text { dispersion }\end{array}$ \\
\hline$c_{\mathrm{p}}$ & $\begin{array}{l}\text { particle number concentration in the volume } V \text {, } \\
\mathrm{m}^{-3}\end{array}$ & $L^{\mathrm{h}}$ & $\begin{array}{l}\text { lability criterion for the homogeneous case } \\
\text { (Eigen mechanism) }\end{array}$ \\
\hline$D_{i}$ & $\begin{array}{l}\text { diffusion coefficient of the species } i \text { in solution, } \\
\mathrm{m}^{2} \mathrm{~s}^{-1}\end{array}$ & $n$ & $\begin{array}{l}\text { number of electrons involved in the faradaic } \\
\text { process }\end{array}$ \\
\hline $\bar{D}$ & mean diffusion coefficient, $\mathrm{m}^{2} \mathrm{~s}^{-1}$ & $r_{0}$ & radius of the electrode, $\mathrm{m}$ \\
\hline$d$ & $\begin{array}{l}\text { thickness of the ligand layer in the colloidal } \\
\text { particle, } m\end{array}$ & $t$ & time, $\mathrm{s}$ \\
\hline $\bar{d}$ & $\begin{array}{l}\text { thickness of the diffusion layer for a spherical } \\
\text { electrode in the presence of complexing ligands, } \\
\mathrm{m}\end{array}$ & $\begin{array}{l}\text { Greek } \\
\alpha\end{array}$ & $\begin{array}{l}\text { pymbols } \\
\text { parameter rela }\end{array}$ \\
\hline $\begin{array}{l}E_{\mathrm{d}, 1 / 2} \\
E_{\mathrm{d}}\end{array}$ & $\begin{array}{l}\text { half-wave potential for SSCP curve, V } \\
\text { deposition potential, V }\end{array}$ & & $\begin{array}{l}\text { thickness of the diffusion layer at the consuming } \\
\text { surface, } m\end{array}$ \\
\hline$F$ & Faraday constant, $\mathrm{C} \mathrm{mol}{ }^{-1}$ & $\bar{\delta}$ & average of thickness of the diffusion layer, $\mathrm{m}$ \\
\hline & $\begin{array}{l}\text { limiting deposition current, A } \\
\text { stripping current, A }\end{array}$ & $\varepsilon$ & $\begin{array}{l}\text { ratio of the diffusion coefficients of bound and } \\
\text { free metal }\end{array}$ \\
\hline$J^{*}$ & $\begin{array}{l}\text { limiting metal flux into the electrode, } \\
\mathrm{mol} \mathrm{m}^{-2} \mathrm{~s}^{-1}\end{array}$ & $\begin{array}{l}\gamma \\
\Gamma_{\mathrm{L}}\end{array}$ & $\begin{array}{l}\text { constant fraction of } \delta \text {, independent of } D^{\alpha} \\
\text { surface ligand concentration, } \mathrm{mol} \mathrm{m}{ }^{-2}\end{array}$ \\
\hline$J_{\text {dif }}^{*}$ & maximum diffusive flux, $\mathrm{mol} \mathrm{m}{ }^{-2} \mathrm{~s}^{-1}$ & $\mu$ & reaction layer thickness, $\mathrm{m}$ \\
\hline$J_{\text {kin }}^{\text {dif }}$ & local kinetic flux, $\mathrm{mol} \mathrm{m}^{-2} \mathrm{~s}^{-1}$ & $\tau$ & transition (stripping) time, $\mathrm{s}$ \\
\hline$K$ & complexation constant, $\mathrm{mol}^{-1} \mathrm{~m}^{3}$ & $\tau_{\mathrm{M}}^{*}$ & limiting transition time in the absence of com- \\
\hline $\begin{array}{l}K^{\prime} \\
k_{\mathrm{a}}\end{array}$ & $\begin{array}{l}=K c_{\mathrm{L}, \mathrm{T}} \\
\text { association rate constant of the complex } \mathrm{ML} \text {, }\end{array}$ & $\tau_{\mathrm{M}+\mathrm{L}}^{*}$ & $\begin{array}{l}\text { plexing ligands, } \mathrm{s} \\
\text { limiting transition time in the presence of com- }\end{array}$ \\
\hline & $\mathrm{mol}^{-1} \mathrm{~m}^{3} \mathrm{~s}^{-1}$ & & \\
\hline
\end{tabular}

Stripping chronopotentiometry (SCP) is a technique that is relatively insensitive to organic adsorption interferences $[8,9]$ while having a detection limit comparable to that of pulsed stripping voltammetries. Even more relevant here is that for the complete depletion mode of scanned stripping chronopotentiometry (SSCP) [10] a known rigorous equation is available for the full wave in the kinetic current regime [11]. Using this expression we demonstrated that the characteristic parameters of the SSCP wave (the limiting wave height, $\tau^{*}$, and the half-wave deposition potential, $\Delta E_{\mathrm{d}, 1 / 2}$ ) provide an indicator of changes in lability of metal complex systems [12].

The objective of the present work is to extend the dynamic theory for colloidal metal complexes with a lability criterion for a steady-state situation in which convective diffusion is the dominant mode of mass transport. Support- ing experimental evidence is provided by SSCP measurements of $\mathrm{Pb}$ (II) and $\mathrm{Cd}(\mathrm{II})$ complexation in dispersions of carboxylated latex particles.

\section{Theory}

\subsection{Dynamic speciation of colloidal metal complexes}

Let us consider a homodisperse colloidal ligand dispersion with spherical particles of radius $a$, where the ligand groups are located in a thin outer shell of thickness $d$ $(d \ll a)$. This picture applies to, e.g., synthetic core-shell colloids and to humic matter adsorbed at the surface of solid particles in natural waters. If the thickness of the ligand layer is indeed much smaller than the particle size we can integrate the ligand concentration over the shell 
volume and express the result in terms of an equivalent surface concentration, $\Gamma_{\mathrm{L}}[1]$

$\int_{a}^{a+d} c_{\mathrm{L}} 4 \pi r^{2} \mathrm{~d} r=\Gamma_{\mathrm{L} / \mathrm{A}}$

We further consider a metal ion $\mathrm{M}$ that can (i) associate with a binding site, $L$, in the shell, to generate a colloidal complex, ML and (ii) be reduced to metal atoms $\mathrm{M}^{0}$ at an electrode

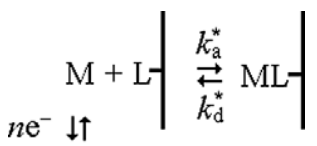

$$
\begin{aligned}
& \mathrm{M}^{0}
\end{aligned}
$$

The overall particle radius $(a+d)$ will be assumed to be small compared with the thickness of the macroscopic diffusion layer thickness, $\delta$, developed at the electrode/dispersion interface. Hence the metal ion concentration gradient is immaterial on the size scale of an individual particle. The apparent rate constants of complex formation and dissociation in colloidal ligand dispersions, $k_{\mathrm{a}}^{*}$ and $k_{\mathrm{d}}^{*}$, are related to the $k_{\mathrm{a}}$ and $k_{\mathrm{d}}$ in a homogeneous solution by [1]:

$k_{\mathrm{a}}^{*^{\prime}}=k_{\mathrm{a}}^{\prime} /\left(1+k_{\mathrm{a}}^{\prime}\left(4 \pi a D_{\mathrm{M}} c_{\mathrm{p}}\right)^{-1}\right)$

$k_{\mathrm{d}}^{*}=k_{\mathrm{d}} /\left(1+k_{\mathrm{a}}^{\prime}\left(4 \pi a D_{\mathrm{M}} c_{\mathrm{p}}\right)^{-1}\right)$

where $D_{\mathrm{M}}$ is the diffusion coefficient of the metal and $c_{\mathrm{p}}$ is the particle number density. The $k_{\mathrm{a}}^{*^{\prime}}$ and $k_{\mathrm{a}}^{\prime}$ are useful under conditions of excess of ligand

$k_{\mathrm{a}}^{*^{\prime}}=k_{\mathrm{a}}^{*} C_{\mathrm{L}} \quad$ and $\quad K^{\prime}=k_{\mathrm{a}}^{*^{\prime}} / k_{\mathrm{d}}^{*}=K C_{\mathrm{L}}$

where $K$ is the stability constant of the colloidal complex $\mathrm{ML}$ and $C_{\mathrm{L}}$ is the smeared-out total ligand concentration [1]. Other symbols have their usual meaning. The association rate constant, $k_{\mathrm{a}}$, is usually consistent with a mechanism in which formation of an outer-sphere complex between the metal and the ligand, with an electrostatically determined stability constant $\left(K_{\mathrm{os}}\right)$, is followed by a ratelimiting removal of water from the inner coordination sphere of the metal $\left(k_{-\mathrm{w}}\right)$, commonly known as the Eigen mechanism [13].

For a colloidal ligand dispersion, the apparent rate constants, $k_{\mathrm{a}}^{*^{\prime}}$ and $k_{\mathrm{d}}^{*}$, have two limiting values:

(i) a kinetic limit for $k_{\mathrm{a}}^{\prime}\left(4 \pi a D_{\mathrm{M}} c_{\mathrm{p}}\right)^{-1} \ll 1$, at which $k_{\mathrm{a}}^{*^{\prime}}=k_{\mathrm{a}}^{\prime}$ and $k_{\mathrm{d}}^{*}=k_{\mathrm{d}}$. This situation occurs for metals with relatively low formation rate constants (low $\left.k_{-\mathrm{w}}\right)$ and/or systems with small particles,

(ii) a diffusive limit for $k_{\mathrm{a}}^{\prime}\left(4 \pi a D_{\mathrm{M}} c_{\mathrm{p}}\right)^{-1} \gg 1$, at which $k_{\mathrm{a}}^{*^{\prime}}=4 \pi a D_{\mathrm{M}} c_{\mathrm{p}}$ and $k_{\mathrm{d}}^{*}=4 \pi a D_{\mathrm{M}} c_{\mathrm{p}} / K^{\prime}$, respectively. This limit is expected for metals with relatively high $k_{- \text {w }}$ values and/or relatively large colloidal particles.

Following the concepts established for homogeneous solutions [14], a metal complex system is denoted as dynamic if the apparent rates of the complex formation/ dissociation reactions are fast on the experimental time scale, $t$, i.e.,

$k_{\mathrm{a}}^{*^{\prime}} t, k_{\mathrm{d}}^{*} t \gg 1$ dynamic

If condition (5) is met then equilibrium is fully maintained in the bulk volume of the system. At the other extreme, a system for which $k_{\mathrm{a}}^{*^{\prime}} t, k_{\mathrm{d}}^{*} t \ll 1$ is denoted as static (inert).

In the presence of an ongoing interfacial process, e.g., consumption of $M$ at an electrode surface, the overall flux of $M$ towards the electrode is simultaneously determined by the diffusion and kinetics of interconversion between $M$ and its complex species in the system. The contribution of complexes to the metal flux depends on the relative magnitudes of the diffusive and kinetic fluxes, $J_{\text {dif }}^{*}$ and $J_{\mathrm{kin}}^{*}$, respectively. The lability criterion, $L$, is defined as the ratio $J_{\text {kin }}^{*} / J_{\text {dif }}^{*}$. The well-known limits for dynamic systems are labile (diffusion control) and non-labile (kinetic control) [14]

$L=J_{\text {kin }}^{*} / J_{\text {dif }}^{*} \begin{cases}\gg 1 & \text { labile } \\ \ll 1 & \text { non-labile }\end{cases}$

\subsection{Dynamic information obtained by SSCP}

SSCP is a useful tool to obtain dynamic metal speciation information because the analytical signal (the transition time, $\tau$ ) always reflects the magnitude of the original deposition flux, irrespective of its nature (i.e., diffusioncontrolled or kinetically controlled). The thermodynamic complex stability constant, $K$, can be calculated from the shift in the half-wave deposition potential, $\Delta E_{\mathrm{d}, 1 / 2}$, (analogous to the DeFord-Hume expression) irrespective of the degree of lability of the system [12]

$\ln \left(1+K^{\prime}\right)=-(n F / R T) \Delta E_{\mathrm{d}, 1 / 2}-\ln \left(\tau_{\mathrm{M}+\mathrm{L}}^{*} / \tau_{\mathrm{M}}^{*}\right)$

where $\tau_{\mathrm{M}+\mathrm{L}}^{*}$ and $\tau_{\mathrm{M}}^{*}$ denote the $\tau$ values for limiting deposition current conditions in the presence and in the absence of ligand, respectively.

In colloidal ligand systems, a lower amount of reduced metal and thus a lower $\tau$ value generally arises from the reduced diffusion coefficient of the colloidal ML species. Further reduction of $\tau$ results if the colloidal complex is not fully labile. A decrease in $c_{\mathrm{M}^{0}}^{*}$ shifts the SSCP wave to more positive potentials due to the effect of lower $c_{\mathrm{M}^{0}}^{*}$ on $E_{\text {eq }}$ at $t=0$ [15]. Thus any decrease in $\tau$ due to the presence of complexing ligands concomitantly increases $E_{\mathrm{d}, 1 / 2}$, (i.e., reduces the negative potential shift) and a consistent relationship is maintained between $E_{\mathrm{d}, 1 / 2}$ and $K$ (Eq. (7)).

For quasi-labile or non-labile complexes the apparent association rate constant $k_{\mathrm{a}}^{*^{\prime}}$ can be calculated from the limiting $\tau$ (i.e., $\tau^{*}$ ) using the known expression for the thickness of the pertaining reaction layer, $\mu[16]$

$\mu=\left(D_{\mathrm{M}} / k_{\mathrm{a}}^{*^{\prime}}\right)^{1 / 2}$ 
For a known $D_{\mathrm{ML}}, \mu$ can be obtained from the change in $\tau^{*}$ due to the presence of complexing ligands

$$
\tau_{\mathrm{M}+\mathrm{L}}^{*} / \tau_{\mathrm{M}}^{*}=\left[D_{\mathrm{M}}\left(1+K^{\prime}\right) / d_{\mathrm{M}}\left((\bar{d}-\mu) / \bar{D}\left(1+K^{\prime}\right)+\mu / D_{\mathrm{M}}\right)^{-1}\right]
$$

where $d_{\mathrm{M}}$ and $\bar{d}$ are the thicknesses of the diffusion layer for a spherical electrode (for instance a static mercury drop electrode) in the absence and presence of complexing ligands, respectively,

$d_{\mathrm{M}}=\left(1 / \delta_{\mathrm{M}}+1 / r_{0}\right)^{-1}$

$\bar{d}=\left(1 / \bar{\delta}+1 / r_{0}\right)^{-1}$

with $\bar{\delta}$ and $\delta_{\mathrm{M}}$ representing the thickness of the macroscopic diffusion layer in the presence and absence of complexing ligands, and $r_{0}$ is the electrode radius. In passing we note that the above reasoning is valid for microelectrodes as long as the condition $(a+d) \ll r_{0}$ is satisfied. The diffusion layer thicknesses, $d_{\mathrm{M}}$ and $\bar{d}$, are determined by the hydrodynamic conditions prevailing in the deposition step, and depend on the diffusion coefficient according to some power function $D^{\alpha}$ of the type

$\delta_{i}=\gamma D_{i}^{\alpha}$

where $\alpha$ is related to the hydrodynamic nature of the mass transport and varies from $1 / 2$ for pure diffusion conditions to $1 / 3$ for laminar convective diffusion [17] and $\gamma$ is a constant.

$\bar{D}$ is the average diffusion coefficient that describes the coupled diffusion of complex and free metal under labile conditions [3]

$$
\begin{aligned}
\bar{D} & =\left(D_{\mathrm{M}} C_{\mathrm{M}}+D_{\mathrm{ML}} C_{\mathrm{ML}}\right) /\left(C_{\mathrm{M}}+C_{\mathrm{ML}}\right) \\
& =D_{\mathrm{M}}\left(1+\varepsilon K^{\prime}\right) /\left(1+K^{\prime}\right)
\end{aligned}
$$

\section{Experimental}

\subsection{Reagents}

All solutions were prepared in ultrapure water from a MilliQ Simplicity (resistivity $>18 \mathrm{M} \Omega \mathrm{cm}$ ). $\mathrm{Cd}(\mathrm{II})$ stock solution was prepared from solid $\mathrm{Cd}\left(\mathrm{NO}_{3}\right)_{2}$ (Merck, p.a.), $\mathrm{Pb}(\mathrm{II})$ stock solution was prepared from dilution of a lead standard solution (1000 mg/L Merck), and $\mathrm{NaNO}_{3}$ stock solution was prepared from the solid (Merck, suprapur). Stock solutions of MES (2- $(N$-morpholino) ethanesulfonic acid) and MOPS (3-( $N$-morpholino)propanesulfonic acid) buffers were prepared from the solids (Fluka, Microselect, $>99.5 \%$ ). $\mathrm{HNO}_{3}$ (Merck, suprapur) and $\mathrm{NaOH}$ (solid from Riedel-de Haën) solutions were used to adjust the $\mathrm{pH}$. Stock dispersions of carboxylated latex nanospheres $(10 \%(\mathrm{w} / \mathrm{w}))$ were obtained from Bangs Labs (US): $(a+d)=15 \mathrm{~nm}, c_{\mathrm{L}, \mathrm{t}}=6.50 \times 10^{-5} \mathrm{~mol} \mathrm{COOH}$ per gram and from Ikerlat Polymers (Spain): $(a+d)=$ $40.0 \mathrm{~nm}, c_{\mathrm{L}, \mathrm{t}}=5.2 \times 10^{-5} \mathrm{~mol} \mathrm{COOH}$ per gram; $(a+d)=$
$60.5 \mathrm{~nm}, \quad c_{\mathrm{L}, \mathrm{t}}=5.1 \times 10^{-5} \mathrm{~mol} \mathrm{COOH}$ per gram and $(a+d)=129 \mathrm{~nm} \quad c_{\mathrm{L}, \mathrm{t}}=5.9 \times 10^{-5} \mathrm{~mol} \mathrm{COOH}$ per gram. The latex particle density is $1.06 \times 10^{3} \mathrm{~kg} \mathrm{~m}^{-3}$ and the maximum surface ligand concentration is $3.5 \times 10^{-7} \mathrm{~mol} \mathrm{~m}^{-2}$ for the $15 \mathrm{~nm}$ radius particles, $7.3 \times 10^{-7} \mathrm{~mol} \mathrm{~m}^{-2}$ for the $40 \mathrm{~nm}, 1.1 \times 10^{-6} \mathrm{~mol} \mathrm{~m}^{-2}$ for the $60.5 \mathrm{~nm}$ and $2.7 \times$ $10^{-6} \mathrm{~mol} \mathrm{~m}{ }^{-2}$ for the $129 \mathrm{~nm}$. The $15 \mathrm{~nm}$ nanospheres were cleaned to eliminate surfactant by a mixed bed resin method [18] while the others were cleaned by the manufacturer. An ionic strength of $0.01 \mathrm{M}$ was used in all experiments. Voltammetric experiments were performed using particle concentrations between $0.1 \%$ and $0.4 \%(\mathrm{w} / \mathrm{w})$ and $\mathrm{Pb}(\mathrm{II})$ and $\mathrm{Cd}(\mathrm{II})$ concentrations from 2.0 to $8.0 \times$ $10^{-7} \mathrm{M}$. For the $15 \mathrm{~nm}$ particles a potentiometric titration was performed to determine the degree of deprotonation at each $\mathrm{pH}$, while the other particles were characterized conductimetrically and potentiometrically by the manufacturer.

\subsection{Apparatus}

An Ecochemie Autolab PGSTAT12 potentiostat was used in conjunction with a Metrohm 663VA stand. The electrometer input impedance of this instrument is larger than $100 \mathrm{G} \Omega$. The working electrode was a Metrohm multimode mercury drop electrode (surface area, $4.0 \times 10^{-7} \mathrm{~m}^{2}$, Merck mercury p.a.). The auxiliary electrode was glassy carbon and the reference electrode was a saturated calomel electrode, encased in a $0.1 \mathrm{M} \mathrm{NaNO}$ salt bridge. Measurements were performed at $25^{\circ} \mathrm{C}$ in a reaction vessel thermostated via a Lauda E100 unit. Proton titration experiments were performed using a computer controlled titration stand [19]. The $\mathrm{pH}$ was read using two $\mathrm{pH}$ electrodes and the reference electrode was a $\mathrm{Ag}|\mathrm{AgCl}| \mathrm{KCl}(3 \mathrm{M})$, encased in a $0.01 \mathrm{M} \mathrm{KNO}_{3}$ jacket.

\subsection{Electrochemical parameters}

After the accumulation step an oxidizing strip current, $I_{\text {s }}$, of $1 \times 10^{-9} \mathrm{~A}$ was applied in quiescent solution until the potential reached a value well passed the transition plateau. The $I_{\mathrm{s}}$ values used correspond to conditions approaching complete depletion (I $\tau$ constant). The SSCP waves were constructed from a series of measurements made over a range of deposition potentials, $E_{\mathrm{d}}$. The potential was held at $E_{\mathrm{d}}$ for a deposition time, $t_{\mathrm{d}}$, of $90 \mathrm{~s}$, after which time the oxidizing current was applied.

\section{Results and discussion}

\subsection{Lability criterion for steady-state convective diffusion}

The electrochemical lability criterion for a spherical electrode and convective diffusion can be obtained from the analysis of the general steady-state metal flux to the electrode. This incorporates the mass transport as well as the complex formation/dissociation kinetics $[11,12]$ 


$$
\frac{I_{\mathrm{d}}^{*}}{n F A}=J^{*}=\frac{\bar{D} c_{\mathrm{M}}^{*}\left(1+K^{\prime}\right)}{\bar{d}}\left(1+\frac{\mu \varepsilon K^{\prime}}{\bar{d}}\right)^{-1}
$$

As outlined in Section 2.1, the two limiting cases for a dynamic system, labile and non-labile behavior, arise when the overall flux, $J^{*}$, is limited by diffusion or by the rate of complex dissociation, respectively. The lability criterion, $L^{*}$ (where the asterisk has the same meaning as in $k_{\mathrm{a}}^{*^{\prime}}$ ) can be recognized as the term between brackets in Eq. (13)

$L^{*}=\bar{d} /\left(\mu \varepsilon K^{\prime}\right) \begin{cases}\gg 1 & \text { labile } \\ \ll 1 & \text { non-labile }\end{cases}$

For the labile case the flux becomes $J_{\text {dif }}^{*}$

$J_{\text {dif }}^{*}=\bar{D} C_{\mathrm{M}, \mathrm{T}}^{*} / \bar{d} \quad$ (labile)

and for the non-labile case (assuming $\varepsilon K^{\prime} \gg 1$ ) it becomes $J_{\text {kin }}^{*}$

$J_{\text {kin }}^{*}=\frac{D_{\mathrm{M}} C_{\mathrm{M}}^{*}}{\mu}=k_{\mathrm{d}}^{*}\left(D_{\mathrm{M}} / k_{\mathrm{a}}^{*^{\prime}}\right)^{1 / 2} C_{\mathrm{ML}}^{*} \quad$ (non-labile)

\subsection{Experimental verification of the lability criterion}

To validate this lability expression we compare $L^{*}$ to the values obtained by SSCP measurements on metal ion/carboxylated latex nanospheres systems. More specifically we shall check if the experimental results follow the predicted dependence on the parameters in Eq. (3), i.e., the particle radius, $a$, the ligand concentration, $C_{\mathrm{L}}$, and the particle concentration, $c_{\mathrm{p}}$. The $k_{\mathrm{a}}$ value, as defined by $k_{-\mathrm{w}}$ and $K_{\mathrm{os}}$ is effectively a constant for a given metal ion, ligand charge, and ionic strength of the solution [13].

\subsubsection{Influence of $C_{L}$ and $c_{p}$}

The ligand concentration $C_{\mathrm{L}}$ and the particle concentration $c_{\mathrm{p}}$ are related through the surface ligand concentration $\Gamma_{\mathrm{L}}$

$\Gamma_{\mathrm{L}}=C_{\mathrm{L}} /\left(4 \pi a^{2} c_{\mathrm{p}}\right)$

Eq. (3a) can thus be rewritten in terms of $\Gamma_{\mathrm{L}}$

$k_{\mathrm{a}}^{*^{\prime}}=k_{\mathrm{a}}^{\prime} /\left(1+k_{\mathrm{a}} a \Gamma_{\mathrm{L}} / D_{\mathrm{M}}\right)$

The ligand concentration $\left(C_{\mathrm{L}}\right)$ can be changed either by (i) changing the particle concentration, where its variation is coupled with $c_{\mathrm{p}}$ while the surface concentration $\Gamma_{\mathrm{L}}$ remains constant, or (ii) changing the $\mathrm{pH}$, thus changing the degree of protonation of the binding sites on the colloidal particle. The latter option comes to effectively increasing $C_{\mathrm{L}}$ and $\Gamma_{\mathrm{L}}$, while maintaining $c_{\mathrm{p}}$ constant. Fig. 1 compares the variation of $L^{*}$ with $C_{\mathrm{L}}$ for $\mathrm{Pb}(\mathrm{II})$ binding by latex particles (40 $\mathrm{nm}$ radius) as prescribed by Eq. (16) with the corresponding analogous homogeneous ligand solution for the same mobility of the complex species. In all cases the predicted lability of the colloidal dispersion is significantly less than that for the corresponding homo-

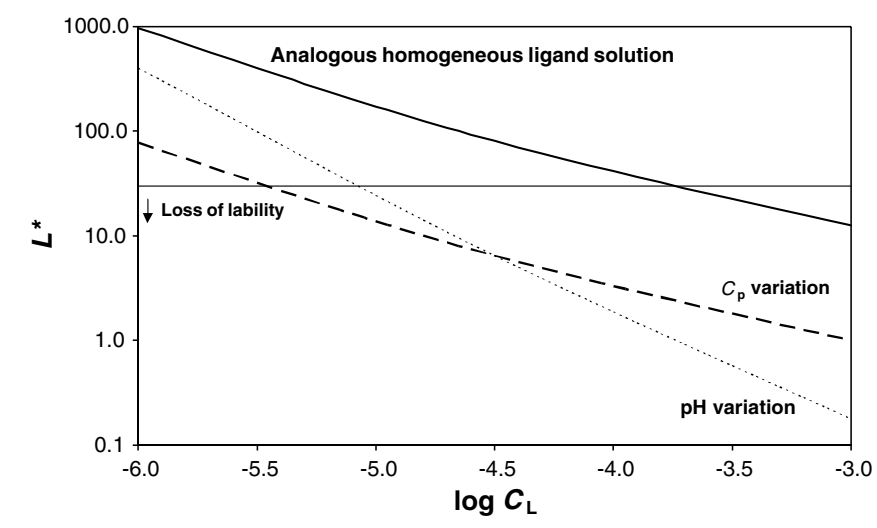

Fig. 1. Variation of the lability criterion, $L^{*}$, with ligand concentration, $C_{\mathrm{L}}\left(\mathrm{mol} \mathrm{m}^{-3}\right)$ for $\mathrm{Pb}(\mathrm{II})$ interaction with colloidal ligand dispersions of $40 \mathrm{~nm}$ radius particles and the analogous homogeneous ligand solution (solid line) for $c_{\mathrm{p}}$ variation (dashed line) $\left(\Gamma_{\mathrm{L}}=1.5 \times 10^{-7} \mathrm{~mol} \mathrm{~m}^{-2}\right)$ and $\mathrm{pH}$ variation (dotted line) $\left(c_{\mathrm{p}}=1.07 \times 10^{19} \mathrm{~m}^{-3}\right)$. Other parameters: $I=0.01 \mathrm{M}, d_{\mathrm{M}}=2.5 \times 10^{-5} \mathrm{~m}, K=10^{7} \mathrm{M}^{-1}, D_{\mathrm{Pb}}=9.9 \times 10^{-10} \mathrm{~m}^{2} \mathrm{~s}^{-1}$, $k_{-\mathrm{w}(\mathrm{Pb})}=7 \times 10^{9} \mathrm{~s}^{-1}, K_{\mathrm{os}}=3.66 \times 10^{-3} \mathrm{~mol}^{-1} \mathrm{~m}^{3}\left(z_{\mathrm{M}^{2} \mathrm{~L}}=-2\right)$.

geneous case. Fig. 1 highlights an interesting feature of metal complexation by colloidal dispersions: the decrease in lability with increasing $C_{\mathrm{L}}$ is dependent on the manner in which the ligand concentration is varied. An increase in $C_{\mathrm{L}}$ invoked by an increase in $\mathrm{pH}$ induces a reduction in $L^{*}$ greater than that due to the same change in $C_{\mathrm{L}}$ realized via an increase in $c_{\mathrm{p}}$. The explanation of this feature lies in inspection of Eq. (18): on increasing the $\mathrm{pH}, \Gamma_{\mathrm{L}}$ increases, and thus $k_{\mathrm{a}}^{*}$ decreases, whereas if $c_{\mathrm{p}}$ is increased both $\Gamma_{\mathrm{L}}$ and $k_{\mathrm{a}}^{*}$ remain constant and the change in lability parallels that of the corresponding homogeneous solution. The distinction between $\mathrm{pH}$ and $c_{\mathrm{p}}$-controlled variation of $C_{\mathrm{L}}$ is a fundamental characteristic of colloidal ligand systems. It is an important practical consideration for interpretation of metal binding by colloidal ligands, and a useful diagnostic tool.

To decide whether variation of $C_{\mathrm{L}}$ by changing $c_{\mathrm{p}}$ or by changing $\mathrm{pH}$ is preferable for determination of the dynamic metal complexation parameters, we must identify the key experimental limitations in SSCP regarding the determination of the thickness of the reaction layer, $\mu$. The determination of $\mu$ requires that the colloidal metal complexes must be quasi- or non-labile. In this situation the SSCP signal is lower than the corresponding signal for the labile case. Thus to minimize the loss of signal on increasing $C_{\mathrm{L}}$, an increase of $c_{\mathrm{p}}$ at constant $\mathrm{pH}$ is preferable. This also has the advantage that the $K$ value will be constant; for polyelectrolytic ligands the apparent $K$ is likely to be dependent on the degree of ligand protonation, i.e., on $\mathrm{pH}$.

Fig. $2 \mathrm{a}$ and $\mathrm{b}$ show the comparison between the experimentally determined and the calculated values of the lability parameter, $L^{*}$, as a function of $C_{\mathrm{L}}$ for lead(II) binding by 40 and $129 \mathrm{~nm}$ radius latex particles, respectively. There is a gratifying agreement for the $40 \mathrm{~nm}$ particles. The results obtained for the $129 \mathrm{~nm}$ particles are very near the 

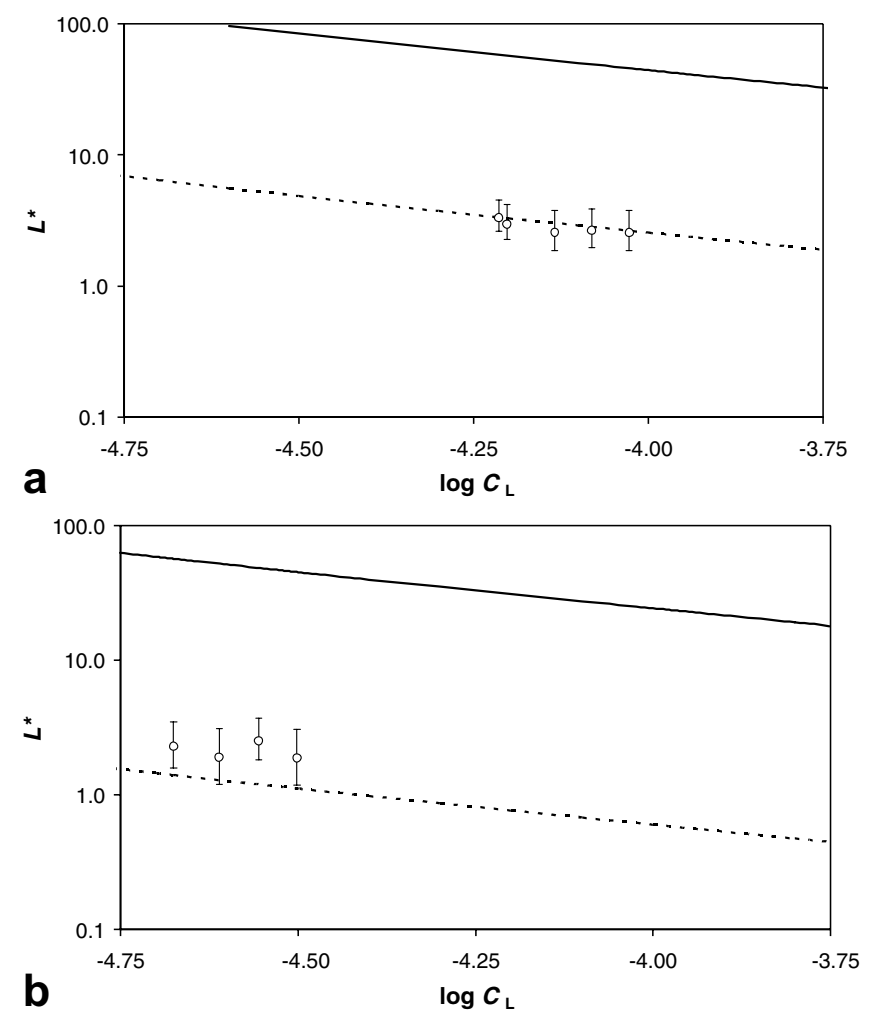

Fig. 2. Experimental verification of the dependence of the lability criterion, $L^{*}$, on the ligand concentration, $C_{\mathrm{L}}\left(\mathrm{mol} \mathrm{m}^{-3}\right)\left(\Gamma_{\mathrm{L}}=2.8 \times\right.$ $10^{-7} \mathrm{~mol} \mathrm{~m}^{-2}$ ) for $\mathrm{Pb}(\mathrm{II})$ interaction with: (a) Carboxylated latex particles of $40 \mathrm{~nm}$ radius. Other parameters: $I=0.01 \mathrm{M}, \mathrm{pH} 6.7, d_{\mathrm{M}}=4.0 \times$ $10^{-5} \mathrm{~m}, \quad K=1.46 \times 10^{7} \mathrm{M}^{-1}, \quad D_{\mathrm{Pb}}=9.9 \times 10^{-10} \mathrm{~m}^{2} \mathrm{~s}^{-1}, \quad k_{-\mathrm{w}(\mathrm{Pb})}=7 \times$ $10^{9} \mathrm{~s}^{-1}, K_{\mathrm{os}}=3.66 \times 10^{-3} \mathrm{~mol}^{-1} \mathrm{~m}^{3}\left(z_{\mathrm{M}^{2} \mathrm{~L}}=-2\right)$. (b) Carboxylated latex particles of $129 \mathrm{~nm}$ radius. Other parameters: $I=0.01 \mathrm{M}, \mathrm{pH} 6.4, d_{\mathrm{M}}=$ $5.7 \times 10^{-5} \mathrm{~m}, \quad K=9.33 \times 10^{7} \mathrm{M}^{-1}, \quad D_{\mathrm{Pb}}=9.9 \times 10^{-10} \mathrm{~m}^{2} \mathrm{~s}^{-1}, \quad k_{-\mathrm{w}(\mathrm{Pb})}=$ $7 \times 10^{9} \mathrm{~s}^{-1}, K_{\mathrm{os}}=3.66 \times 10^{-3} \mathrm{~mol}^{-1} \mathrm{~m}^{3}\left(z_{\mathrm{M}} z_{\mathrm{L}}=-2\right)$. Experimental data (O), calculated from dynamic colloidal theory (dashed line) and for the analogous homogeneous ligand solution (solid line).

detection limit of the technique $\left(\tau_{\mathrm{M}+\mathrm{L}}^{*} \approx 1 \mathrm{~s}\right)$, due to the low mobility $\left(D_{\mathrm{ML}}=1.73 \times 10^{-12} \mathrm{~m}^{2} \mathrm{~s}^{-1}\right)$ and the quasilabile character of the complexes. The evidence is still convincing since the measured values are some 30 times lower than those predicted for the analogous homogeneous case.

\subsubsection{Influence of particle radius}

Increasing the particle radius, $a$, while keeping the ligand concentration $\left(C_{\mathrm{L}}\right)$ constant, implies that the number of particles $c_{\mathrm{p}}$ must decrease accordingly. It also implies a decrease in $D_{\mathrm{ML}}$, meaning that in the calculation of the analogous homogeneous solution we consider the ligands to be homogeneously distributed over the solution volume with a mobility equal to that of the colloidal ligands in the dispersion [7].

Fig. 3 compares the theoretical dependence of the lability criterion $\left(L^{*}\right)$ on the particle radius, $a$, for colloidal ligand dispersions with that for the analogous homogeneous ligand solution. By keeping $C_{\mathrm{L}}$ constant, the surface concentration $\Gamma_{\mathrm{L}}$ changes, hence the observed variations in $L^{*}$ are effectively due to changes in $a \Gamma_{\mathrm{L}}$ (Eq. (18)). As

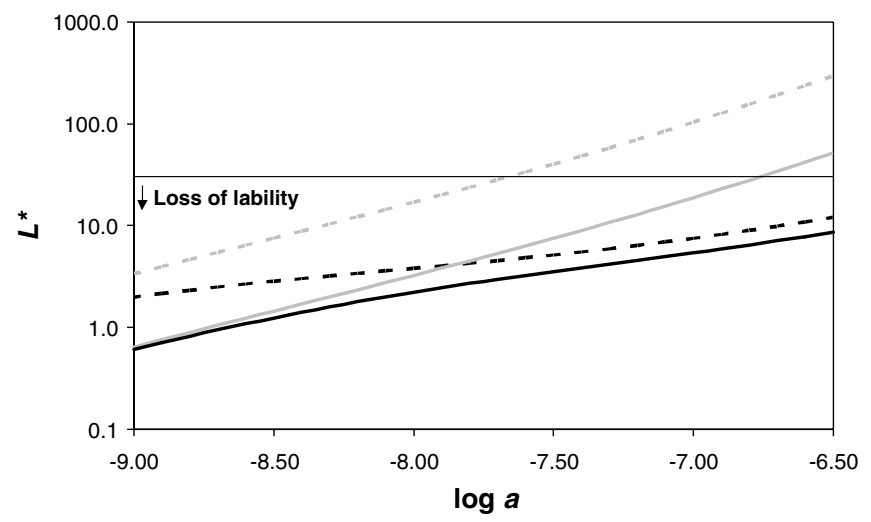

Fig. 3. Theoretical variation of the lability criterion, $L^{*}$, with particle radius, $a(\mathrm{~m})$, for the dynamic theory for colloidal ligand dispersions (black lines) and the analogous homogeneous ligand solution (grey lines), for $\mathrm{Pb}$ (II) (dashed line) and $\mathrm{Cd}$ (II) (full line) in the presence of $C_{\mathrm{L}}=10 \times 10^{-3} \mathrm{~mol} \mathrm{~m}^{-3}$ binding sites. Other parameters: $I=0.01 \mathrm{M}$, $d_{\mathrm{M}}=3.0 \times 10^{-5} \mathrm{~m}, \quad K=1 \times 10^{7} \mathrm{M}^{-1}, \quad D_{\mathrm{Pb}}=9.9 \times 10^{-10} \mathrm{~m}^{2} \mathrm{~s}^{-1}, \quad D_{\mathrm{Cd}}=$ $7.0 \times 10^{-10} \mathrm{~m}^{2} \mathrm{~s}^{-1}, \quad k_{-\mathrm{w}(\mathrm{Pb})}=7 \times 10^{9} \mathrm{~s}^{-1}, \quad k_{-\mathrm{w}(\mathrm{Cd})}=3 \times 10^{8} \mathrm{~s}^{-1}, \quad K_{\mathrm{os}}=$ $3.66 \times 10^{-3} \mathrm{~mol}^{-1} \mathrm{~m}^{3}\left(z_{\mathrm{M}} z_{\mathrm{L}}=-2\right)$.

observed before for the diffusion-controlled techniques [7], the increase in lability of colloidal metal complexes with increasing $a$ is significantly toned down as compared with the analogous homogeneous ligand solution. This effect is more important for $\mathrm{Pb}$ (II) than for $\mathrm{Cd}(\mathrm{II})$ due to the higher $k_{\mathrm{a}}$ of the former.

Fig. 3 does not include experimental data due to the difficulty in obtaining fully comparable results for the different particle radii. This arises from the surface concentration $\Gamma_{\mathrm{L}}$ dependency on the particle radius (Eq. (17)). Therefore, we present the experimental and corresponding theoretical values in Table 1. Consistent with the results presented above for the variation of $C_{\mathrm{L}}$, the experimental values of the lability parameter agree quite well with the predicted ones and are significantly smaller than those for the analogous homogeneous solution.

The values of $K^{\prime}$ and $C_{\mathrm{L}}$ are different for each particle and this makes the lability comparison more involved. Nonetheless it can be seen that for $\mathrm{Pb}(\mathrm{II})$ an increase of the particle radius from $15 \mathrm{~nm}$ (line 3) to $40 \mathrm{~nm}$ (line 5) results in an experimental increase of $L^{*}$ from 0.7 to 2.6, almost identical to the calculated increase from 0.7 to 2.7, but much smaller than the increase from 2.3 to 46 for the analogous homogeneous ligand solution.

Further developments will require the investigation of the polyelectrolytic effect on the stability constant and its effect on the lability of metal complexes in colloidal ligand dispersions. A rough estimate provides a separation between charges of about $1.5 \mathrm{~nm}$ for our fully deprotonated systems. This clearly suggests that understanding the coupling of changes of ligand concentration due to variation of $\mathrm{pH}$ with polyelectrolytic counterion binding effects is fundamental in the understanding of the dynamic behavior of trace metals in natural waters, especially those with low ionic strength and/or variable $\mathrm{pH}$. 


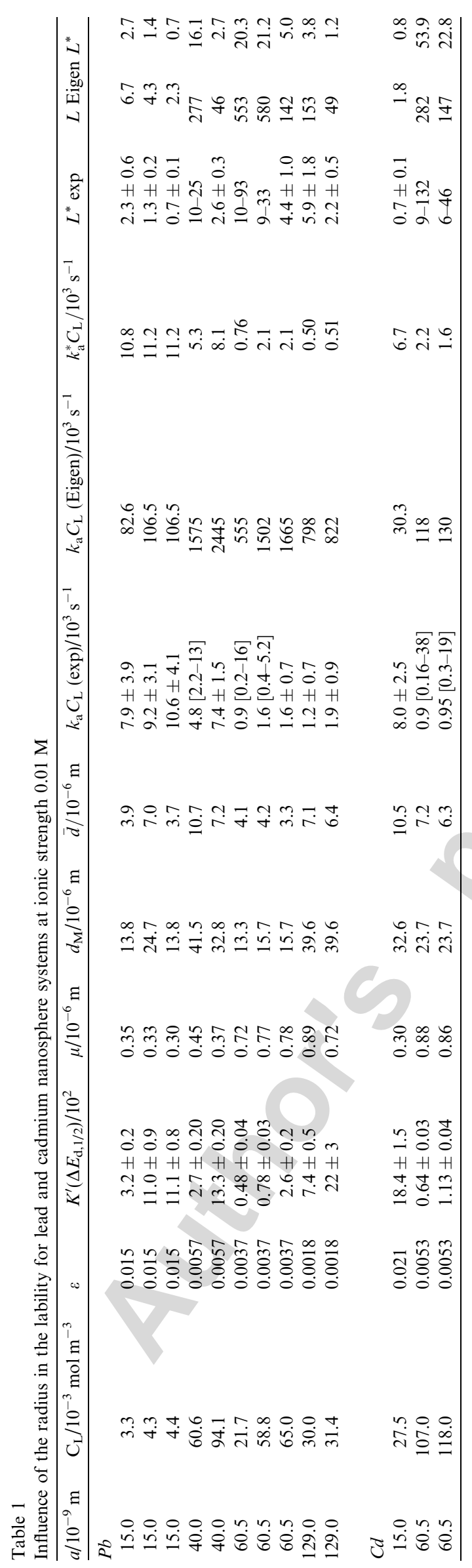

\section{Conclusions}

A lability criterion has been formulated for colloidal metal complexes in stirred solutions where convective diffusion is the dominant mode of mass transport. The predicted values for colloidal complexes of $\mathrm{Pb}$ (II) and $\mathrm{Cd}(\mathrm{II})$ in carboxyl modified latex dispersions, and their dependence on ligand concentration and particle radius, are in good agreement with experimental data. In colloidal ligand dispersions the observed increase in lability with increasing particle radius is significantly toned down as compared with the analogous homogeneous ligand solution, in accord with earlier predictions [7].

The conventional approach of assuming a smeared-out ligand distribution overestimates the lability of a colloidal ligand system. The dependence of lability on the variation of $C_{\mathrm{L}}$ depends strongly on the way in which this parameter is manipulated: a pH increase invokes a greater loss of lability than does an increase in $c_{\mathrm{p}}$. This feature is characteristic of the spatial distribution of the sites in a colloidal dispersion and is therefore fundamental to interpretation of metal speciation in such systems.

\section{Acknowledgments}

We thank Prof. R.M. Town from University of Southern Denmark for helpful comments. We thank Dr. Joxe Sarobe and Ikerlat Polymers (Spain) for the cleaning and characterization (conductimetric and potentiometric) of the $40,60.5$ and $129 \mathrm{~nm}$ carboxylated latex particles. This work was performed within the framework of the EU project ECODIS (Contract No. 518043), project POCI/QUI/56845/2004 and a PhD grant (RD) SFRH/ BD/8366/2002, Fundação para a Ciência e Tecnologia, Portugal.

\section{References}

[1] J.P. Pinheiro, M. Minor, H.P. van Leeuwen, Langmuir 21 (2005) 8635.

[2] W. Davison, J. Electroanal. Chem. 87 (1978) 395.

[3] H.P. van Leeuwen, J. Buffle, R. Cleven, Pure Appl. Chem. 61 (1989) 255.

[4] J. Galceran, J. Puy, J. Salvador, J. Cecilia, H.P. van Leeuwen, J. Electroanal. Chem. 505 (2001) 85

[5] J. Buffle, K.J. Wilkinson, S. Stoll, M. Filella, J. Zhang, Environ. Sci. Technol. 32 (1998) 2887.

[6] A.M. Mota, M.M. Correia dos Santos, in: A. Tessier, D. Turner (Eds.), Metal Speciation and Bioavailability, John Wiley \& Sons, New York, 1995 (Chapter 5).

[7] J.P. Pinheiro, M. Minor, H.P. van Leeuwen, J. Electroanal. Chem. 587 (2006) 284

[8] R.M. Town, H.P. van Leeuwen, J. Electroanal. Chem. 523 (2002) 1.

[9] R.M. Town, H.P. van Leeuwen, J. Electroanal. Chem. 541 (2003) 51.

[10] H.P. van Leeuwen, R.M. Town, Environ. Sci. Technol. 37 (2003) 3945.

[11] H.P. van Leeuwen, R.M. Town, J. Electroanal. Chem. 561 (2004) 67.

[12] J.P. Pinheiro, H.P. van Leeuwen, J. Electroanal. Chem. 570 (2004) 69. 
[13] F.M.M. Morel, J.G. Hering, Principles and Applications of Aquatic Chemistry, John Wiley, New York, 1993.

[14] H.P. van Leeuwen, Electroanalysis 13 (2001) 826.

[15] H.P. van Leeuwen, R.M. Town, J. Electroanal. Chem. 536 (2002) 129.

[16] J. Heyrovský, J. Kůta, Principles of Polarography, Publishing House of the Czechoslovak Academy of Sciences, Praha, and Academic Press, New York, 1966.
[17] V.G. Levich, Physicochemical Hydrodynamics, Prentice-Hall, Englewood Cliffs, NJ, 1962.

[18] M.C. Wilkinson, J. Hearn, P.A. Steward, Adv. Coll. Int. Sci. 81 (1999) 77.

[19] D.G. Kinniburgh, C.J. Milne, P. Venema, Soil Sci. Am. J. 59 (1995) 417. 